\title{
JSSN Online
}

Journal of Society of Surgeons of Nepal (JSSN) is an official publication of Society of Surgeons of Nepal since 1998. Completing 18 years of continuous print publications on peer reviewed research materials of surgical interests; JSSN has served as a prominent form of communication among surgeons of Nepal with great effort from previous editors and eminent surgeons of the country. We are grateful to them for guiding us to arrive at present volume of the journal.

In today's cut-throat digital environment, the debate is still continuing over the print versus online publication indicating that both have relative merits and demerits. But in context of biomedical journal where there is questions of indexing and impact factor, going digital is a must. Realizing this fact, JSSN has embarked upon the online publication from this issue of Vol. 17 complementing the print edition. On the process of digitization, JSSN has started to archive all past issues into electronic versions. Now anybody can access the past issues of the JSSN and tract down the contents of interest by logging into www. jssn.org.np. The new editorial team led by chief editor Dr. Bikal Ghimire foresees the challenges of maintaining the standard of the journal and enhance the readership response. Our main goal is to meet the norms of getting our journal indexed and encourage the researchers to contribute the quality articles. We focus our effort to improve the quality of contents so that we can have acceptable impact factor of the journal in future.

Considering publising strategy, how should we proceed? Shall we have only online publication? Is it time to say goodbye to our printed formats considering financial cost, utilization of resources and environmental credentials? Most of us would agree that digital revolution has made online publication so easy, inexpensive, fast and interactive so why we need the virtue of print format? However, we can't ignore the feel of the touch of paper in your hands with glossy cover. It can be your prized possession in your bookshelves or display in the library. And where internet access is sometimes impossible, print issues will play a great role to reach across the readers. Hence JSSN will try to get the balance right on both arms. But let's not only publish for the purpose of academic promotion. Let JSSN be the journal to promote research, a platform to communicate among professional colleagues, to raise a voice to change in practice in surgery with new concepts and above all, to cultivate a culture of scientific writing.

\section{Dr.Rupesh Mukhia}

Associate Professor of Surgery

KIST Medical College, Tribhuvan University 